\title{
ANALYSIS OF ADVANCED INVERTER TOPOLOGY FOR RENEWABLE ENERGY GENERATION AND ENERGY STORAGE INTEGRATION INTO AC GRID
}

\author{
Kaspars Kroics $^{1,2}$, Laila Zemite ${ }^{2}$, Gatis Gaigals ${ }^{3}$ \\ ${ }^{1}$ Institute of Physical Energetics, Latvia; ${ }^{2}$ Riga Technical University, Latvia; \\ ${ }^{3}$ Ventspils University College, Latvia \\ kaspars.kroics@gmail.com
}

\begin{abstract}
In renewable energy generation systems energy storage is needed not only to supply power when there is no generation. but also for short term smoothening of the electricity supply. The Quasi-Z-source Inverter (qZSI) allows to integrate energy storage in addition to the other energy sources mainly for output power smoothening. In the paper analysis of the scientific papers is given about this kind of converters and also theoretical and simulation based analysis of basic relations, control principles and scientific analysis that reveals limitations and passive component selection. Also the design of the proportional-resonant controller will be analyzed and discussed in more detail.
\end{abstract}

Keywords: energy storage, grid tied inverter, single phase inverter, quasi Z source inverter.

\section{Introduction}

The cost of electricity produced by renewable energy sources and probabilistic nature of the generation are the major concerns that limit its wider usage. Storage technologies have big potential for smoothing out the electricity supply from these sources and ensuring that the supply of generation matches the demand. Especially, storage can be important in rural areas with a weak grid or even without connection to the utility AC grid.

Typical solution for energy storage integration in the renewable energy system is to use an additional DC-DC or even DC-AC converter that increases the costs [1-3]. Multiport DC-DC converters are becoming more and more popular that can be used for integration of energy sources and batteries or different types of storages into the grid. Usually, a multiport converter is used in combination with the traditional DC-AC converter. Further possible reduction of the size, costs and losses can be obtained with the development of novel multiport DC-AC single stage converters (Fig. 1) having less semiconductor switches and passive elements [4]. Such type of the converter can be designed with a reduced number of components and smaller size in some applications [5-8].

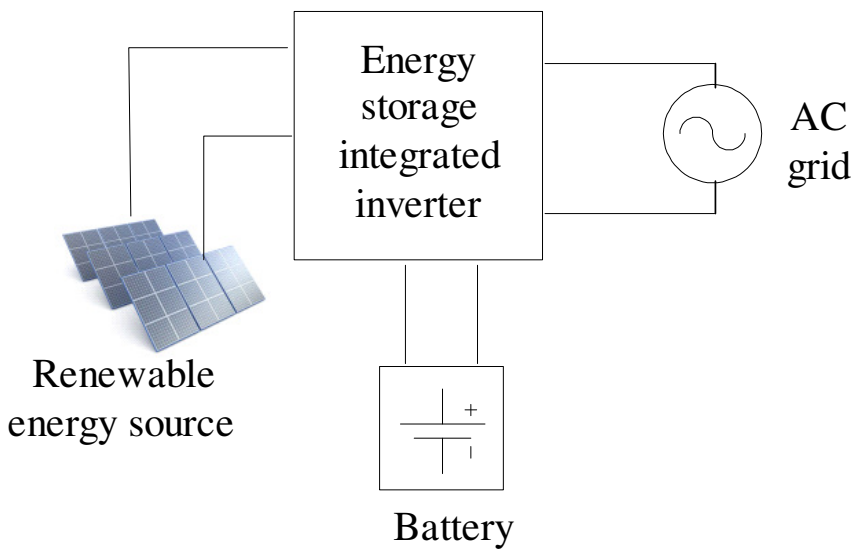

Fig. 1. Structure of energy storage integrated single stage converter

One of the possible solutions is to use the quasi Z-source inverter (qZSI) with integration of energy storage in parallel to the Z-source capacitor without additional passive and semiconductor elements. Scientific papers about this topology are summarized in [9]. The main drawback of such converter is the complex control system to control the energy flow as the change in one parameter influences all energy flows. In this paper a possibility to design such type of converter will be analyzed by using a simplified control structure: proportional - resonant controller with sinusoidal pulse width modulation (PWM) for the inverter converter and the proportional integral controller for control of the shoot through the duty cycle (D) to control power from the input energy source and 
energy storage. The analysis will be based on PSIM software model and simplified mathematical analysis.

\section{Quasi Z-source inverter topology for renewable energy generation and energy storage integration}

Fig. 2. shows schematics of qZSI with an integrated battery. The battery can be connected in parallel to one of the quasi-Z-source capacitors. It is possible to control the output power, and state of charge (SOC) of the battery at the same time by controlling the shoot-through (ST) duty ratio and modulation index [10]. If the battery is connected in parallel to the $C_{2}$, then a low voltage battery (equivalent parameters $V_{B A T}, R_{B A T}$ in Fig. 2) can be used. Connection of the battery in parallel to the lower capacitor $C_{1}$ (equivalent circuit of this connection is shown in Fig. 2 with dotted line $V^{\prime}{ }_{B A T}$, $R_{B A T}{ }_{B A T}$ allows to use the input source with lower voltage. The converter is controlled by means of full bridge inverter transistors and only one additional diode or transistor is needed to provide operation of the converter. With two inductors and capacitors form the quasi $\mathrm{Z}$ source network and by means of the shoot through state of the duty cycle (D) the output voltage can be controlled.

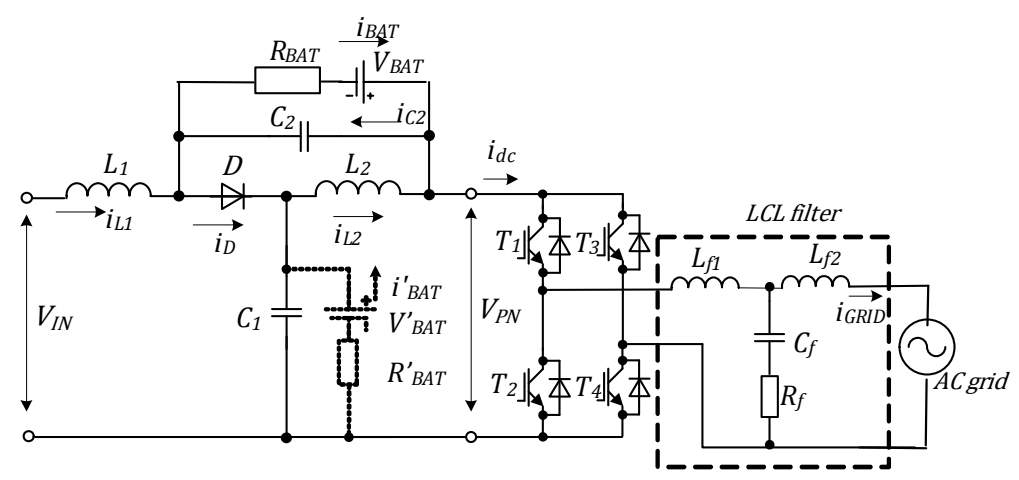

Fig. 2. Quasi-Z source inverter with integrated battery

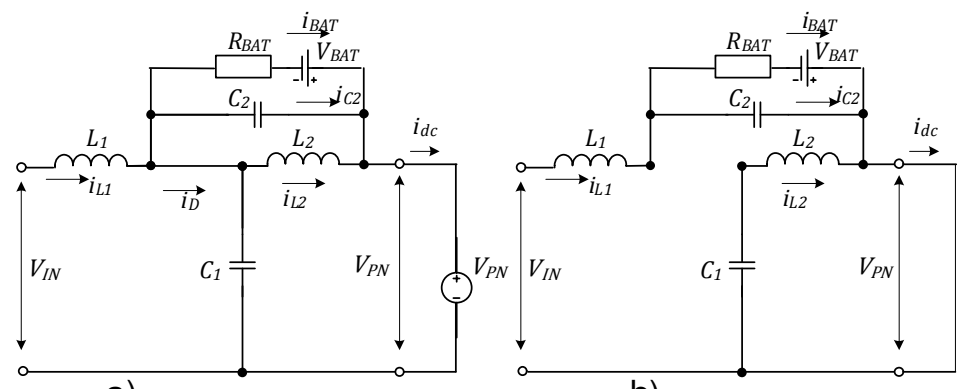

a)

b)

Fig. 3. Equivalent circuits of the converter: a - during non shoot-through state; $\mathrm{b}$ - during shoot-through state

The qZSI with the integrated battery has two operating modes in the continuous conduction mode (CCM): active state and traditional non-shoot-through state. Operation modes of the converter are shown in Fig. 3. Continuous current flows through the diode D during the non shoot-through state and its equivalent circuit is shown in Fig. 3 a. During this time interval, the circuit equations are presented as follows:

$$
\begin{gathered}
L_{1} \frac{d i_{L 1}}{d t}=v_{I N}-v_{C 1}, \\
L_{2} \frac{d i_{L 2}}{d t}=-v_{C 2}, \\
C_{1} \frac{d v_{C 1}}{d t}=i_{L 1}-i_{d c},
\end{gathered}
$$




$$
C_{2} \frac{d v_{C 2}}{d t}=i_{L 2}-i_{d c}-i_{b a t} .
$$

In the shoot-through mode transistors of the inverter are open as a result, the diode $\mathrm{D}$ is turned off due to the reverse bias voltage. Its equivalent circuit is shown in Fig. 3 b. During the ST state, the circuit equations are as follows:

$$
\begin{gathered}
L_{1} \frac{d i_{L 1}}{d t}=v_{I N}+v_{C 2}, \\
L_{2} \frac{d i_{L 2}}{d t}=v_{C 1}, \\
C_{1} \frac{d v_{C 1}}{d t}=-i_{L 2}, \\
C_{2} \frac{d v_{C 2}}{d t}=-i_{L 1}-i_{b a t} .
\end{gathered}
$$

The relation between the variables of the converter can be described mathematically by solving equations that describe both states of the converter and taking into account that average voltage of an inductor over one switching period is zero and also average current of a capacitor over one switching period is zero. Expressions are relatively simple and can be solved analytically. It should be taken into account that in equations parasitic resistances of all elements are not taken into account, the deeper analysis is provided in [11-13]. The final equations for steady-state conditions are as follows:

$$
\begin{gathered}
V_{C 1}=\frac{1-D}{1-2 D} V_{I N}, \\
V_{C 2}=\frac{D}{1-2 D} V_{I N}, \\
V_{P N \max }=\frac{1}{1-2 D} V_{I N} .
\end{gathered}
$$

During ST state:

$$
v_{p n}=0 .
$$

During non-ST state:

$$
V_{C 1}=V_{C 2}+V_{I N} .
$$

If the battery is connected in parallel to the capacitor $C_{1}$, and considering that $V_{B A T}$ is equal to $V_{C 1}$, the following expression can be derived:

$$
V_{P N}=2 V_{B A T}^{\prime}-V_{I N} .
$$

Whereas in case if battery is connected in parallel to the capacitor $C_{2}$, the following expression can be written:

$$
V_{P N}=2 V_{B A T}+V_{I N} .
$$

From this it can be concluded that connection of the battery in parallel with $C_{1}$ is preferable when a battery with higher voltage is required but the input voltage is lower. The battery in parallel with $C_{2}$ is preferable when the battery voltage is low but the input voltage can be higher.

The output power of the inverter can be controlled by manipulating of the output voltage, as the output peak phase voltage of the inverter is:

$$
v_{\text {line } \max }=V_{P N \max } \cdot M,
$$


where $M-$ a modulation index.

Also for the connection of the battery in parallel to $C_{2}$ battery discharge power limitations exist [14] that also must be taken into account:

$$
\begin{aligned}
& P_{B A T}<\frac{D}{1-2 D} P_{I N}, \\
& P_{B A T}<\frac{D}{1-D} P_{\text {OUT }} .
\end{aligned}
$$

The calculation of the parameters of passive components of the quasi Z-source inverter without energy storage is analyzed in many papers, for example, in [15-18]. The difference from traditional qZSI in parameter calculation is that voltage ripple on the capacitors must be lower to limit battery power pulsations, it means that passive component values must be higher that in traditional qZSI.

\section{Control system of energy stored quasi $Z$-source inverter}

The control structure used in simulations of energy stored qZSI is shown in Fig. 4. As there are three power flows: from the PV panel or other energy source, from or to battery and from or to the ac grid, then by controlling two of them the third one is determined [19]. In particular case battery power or input power is controlled by the shoot trough duty cycle D, which is controlled by PI algorithm and the inverter output power is controlled by the modulation index $\mathrm{M}$.

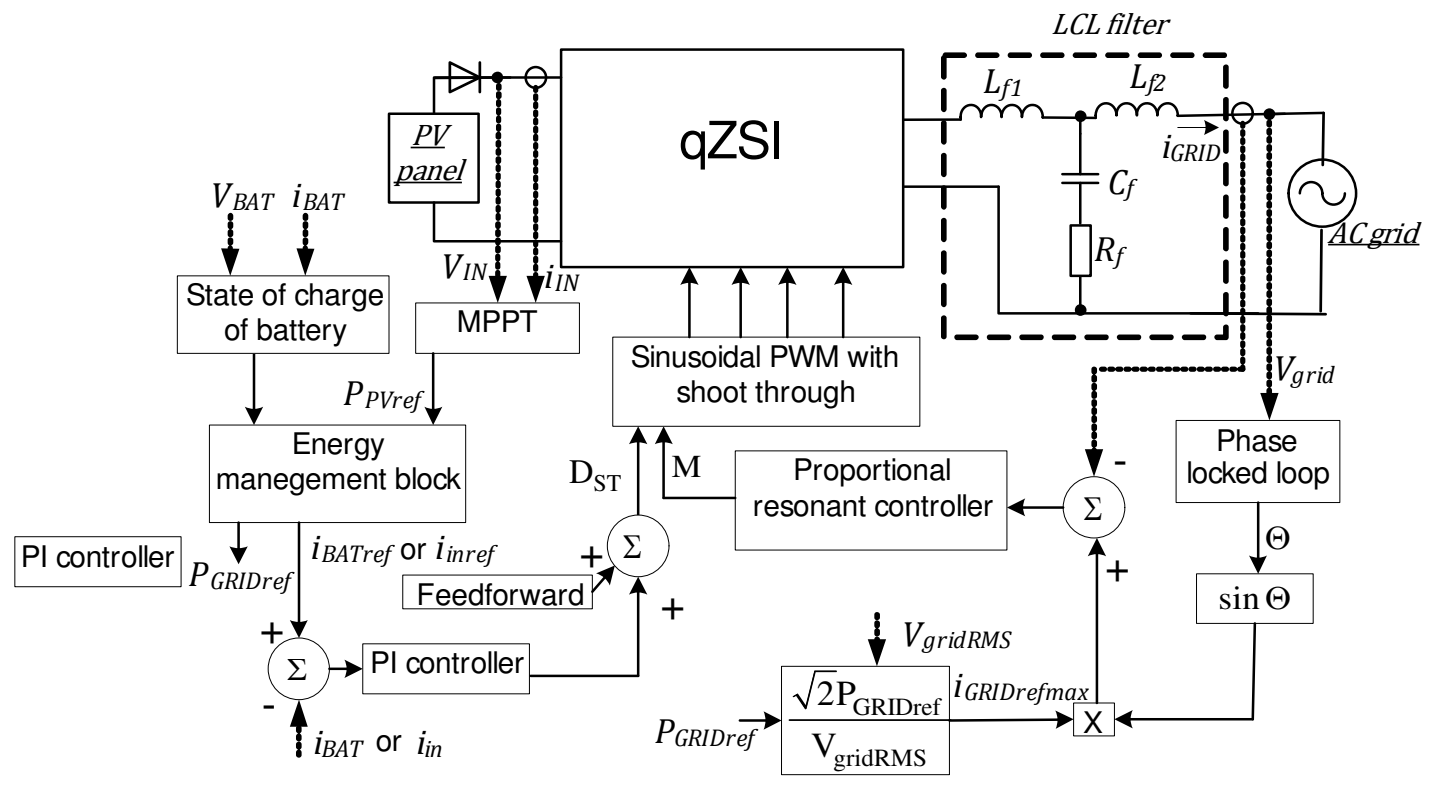

Fig. 4. General control structure of energy stored qZSI

To speed up response and improve stability of the feed forward control is used, the average duty cycle can be calculated by equation expressed from the previous equations (9) - (16). If the battery is connected in parallel to the capacitor $C_{1}$, the equation is as follows:

$$
D_{\text {STaverage }}^{\prime}=\frac{V_{B A T}-V_{I N}}{2 V_{B A T}-V_{I N}}
$$

If the battery is connected in parallel to the upper capacitor $C_{2}$, the equation for average duty cycle can be calculated as follows:

$$
D_{\text {STaverage }}=\frac{V_{B A T}}{V_{I N}+2 V_{B A T}} .
$$

The inverter side of the converter is controlled by using the proportional resonant controller that controls the modulation index M. 


\subsection{Phase locked loop}

Accurate extraction of the grid voltage phase angle and frequency is very important to ensure stable operation of the grid-connected power converter. Comparison of PLL is done in [20-22] and as most promising the Second-Order Generalized Integrator (SOGI) PLL and Park PLL are carried out. As in this case the converter is designed for single phase application, the Park PLL is more difficult to implement, therefore, hybrid SOGI and Park based PLL are used.

Figure 5 shows realization of PLL in PSIM software. The purpose of the orthogonal signal generator block (first elements from the left side till Park block) is to generate the orthogonal signal that can be used in Park transformation. For the orthogonal signal generation other methods also can be used, good comparison of methods is provided in [23]. Mathematics of Park transformation is used to detect the phase. The output of the phase detector is then passed to the PI controller, the output of which is integrated to get the estimated phase angle. As it can be seen in Fig. 6, the PLL synchronizes fast and is stable. There must be solved some challenges, if the PLL structure is implemented in digital control due to system delay.

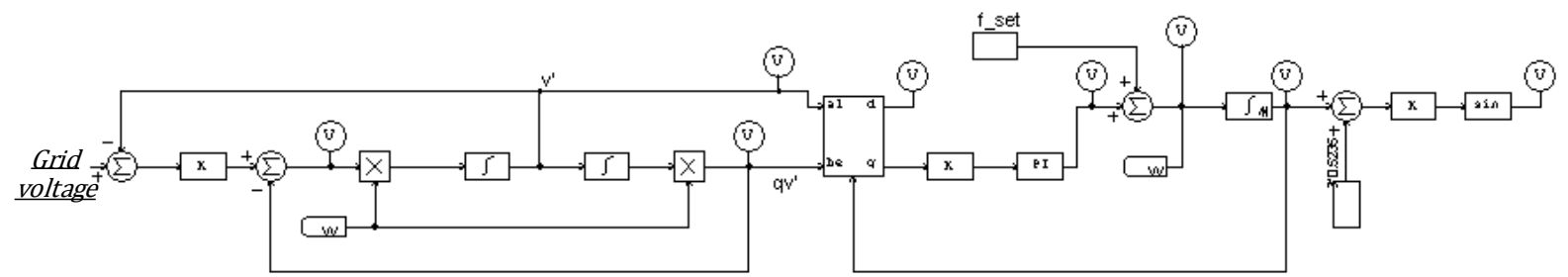

Fig. 5. PLL block in simulation software

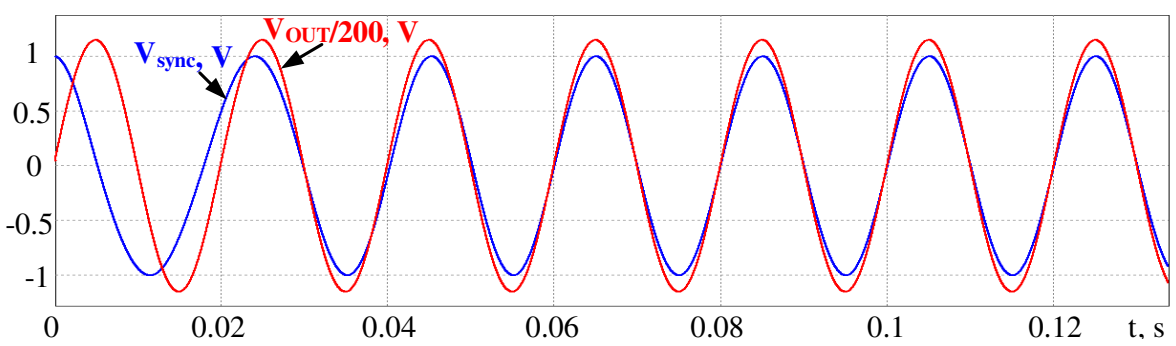

Fig. 6. Grid voltage and output signal of the PLL block

\subsection{Proportional resonant controller}

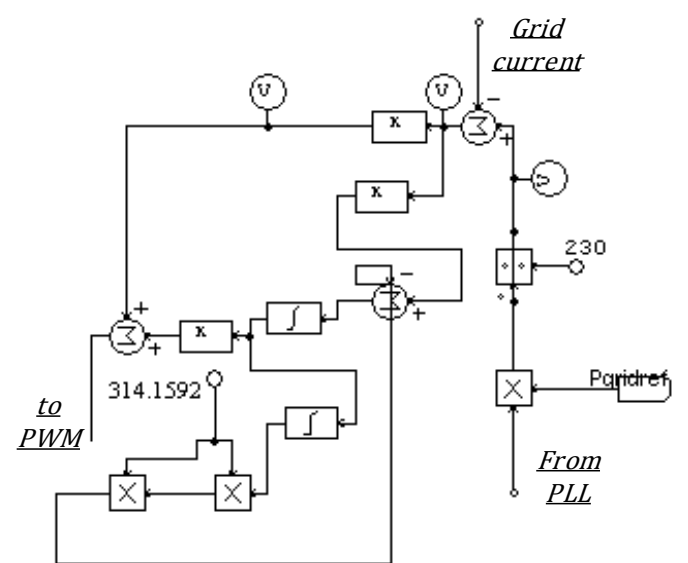

Fig. 7. Grid voltage and output signal of the PLL block

The PR controller is a mix of the proportional and resonant controller. The transfer function of the controller is the following:

$$
G=k_{P}+\frac{k_{i} s}{s^{2}+\omega^{2}},
$$

where $\omega-$ the AC frequency; 
$k_{i}-$ a constant that is carefully selected to shift the magnitude of the controller response.

An ideal PR controller has an infinite gain at the AC frequency and no phase shift and gain at other frequencies. The controller's infinite gain may cause stability problems in practical applications due to limitations of the signal processing system, but in simulation environment this controller works well. Thus a PR controller has much in common with a common PI controller. The difference consists only in the way the integration action takes part. The integrator will only integrate frequencies very close to the resonance frequency and will not introduce stationary error or phase shift. The proportional gain $\mathrm{K}_{\mathrm{p}}$ is tuned in the same way as for the PI controller, it determines the dynamics of the system in terms of the bandwidth phase and gain margin [24].

\subsection{Pulse width modulation implementation}

For the inverter control sinusoidal PWM with added ST states via logic "OR" element is used [25]. The signal from the PR controller is compared with the triangular modulation signal and traditional sinusoidal PWM is formed. The PI controller regulates the shoot through duty cycle D to maintain the desired input or battery power. The duty cycle D is added to the sinusoidal PWM and the shoot through state is formed, in which all of the transistors of the inverter are in on state. The realization of this block in PSIM software is shown in Fig. 8. The example of PWM signals is shown in Fig. 9. V67 is the triangular signal from the carrier generator, $V_{c a r} d s$ is the signal from the PR controller, which is sinusoidal (in the figure only a small piece of the whole sinusoid is shown). V90 is a sinusoidal PWM. To this signal through the "OR" element the ST duty cycle D is added and V41 is the signal that goes to the transistor gate.

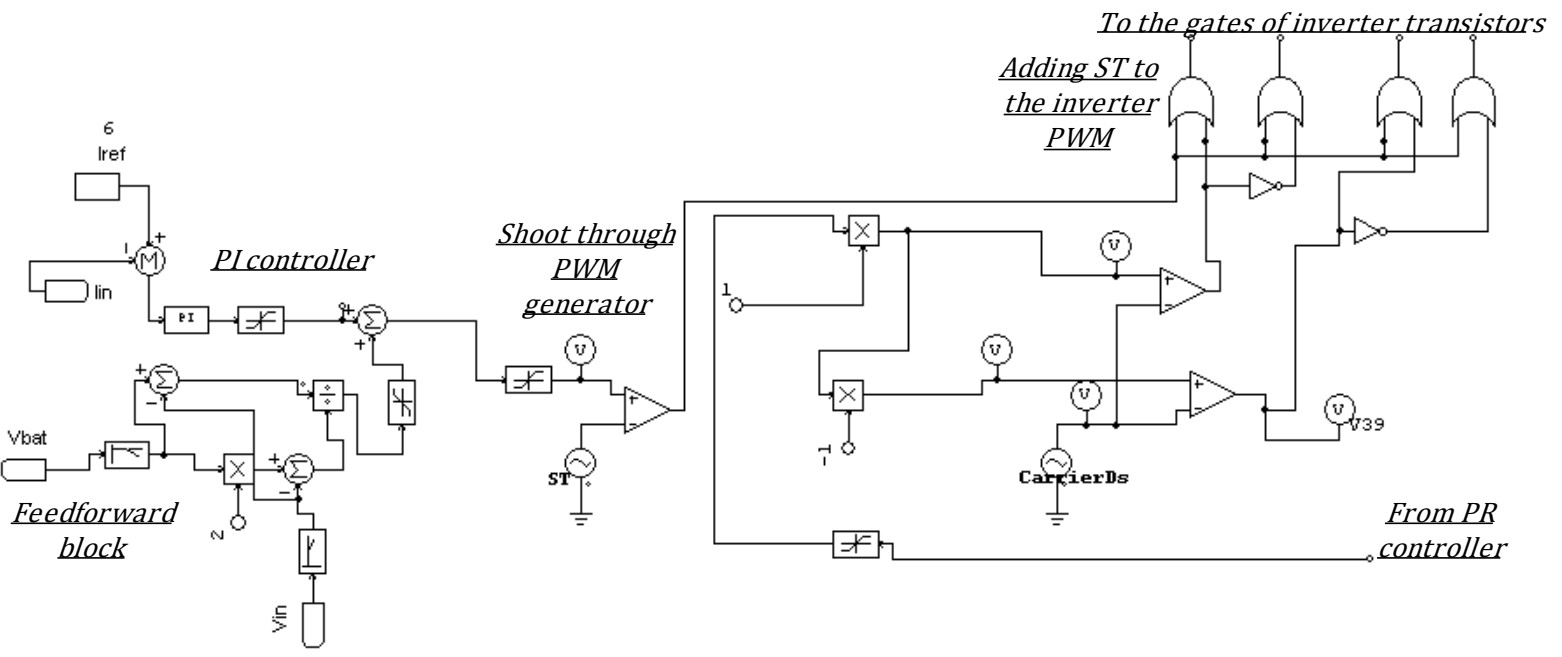

Fig. 8. Grid voltage and output signal of the PLL block
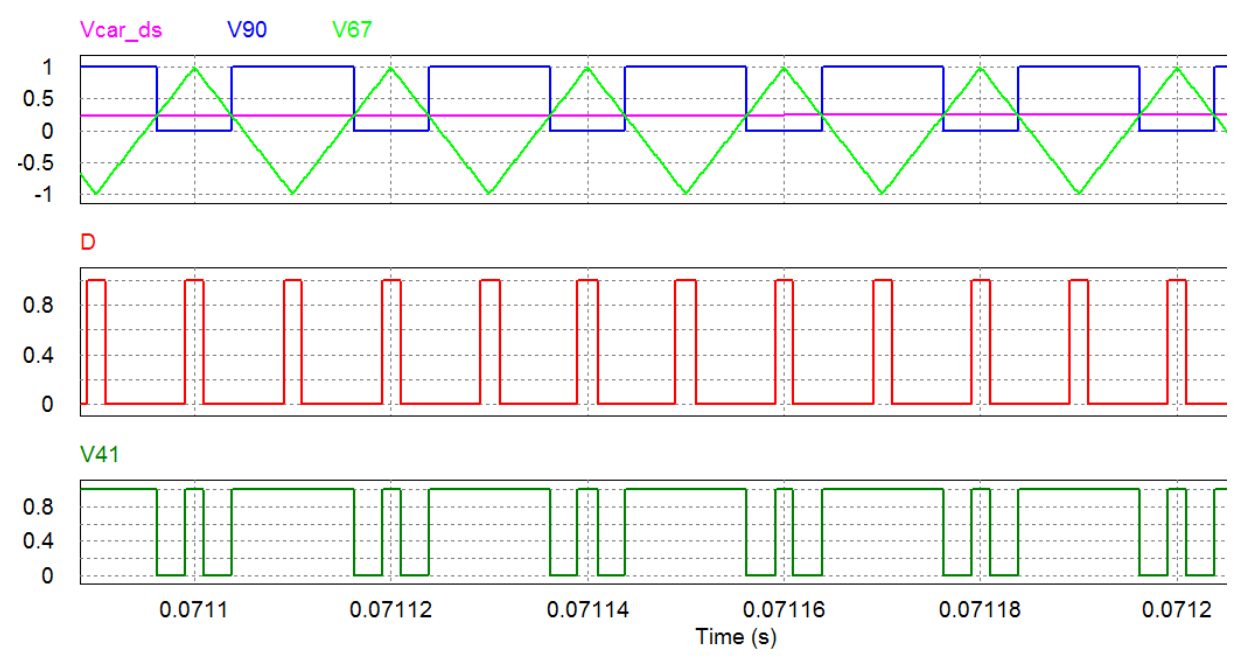

Fig. 9. Grid voltage and output signal of the PLL block 


\section{Simulation results of energy stored quasi Z-source inverter}

The simulation was performed with both possible connections of the energy storage. If the battery is connected in parallel to the upper capacitor $\mathrm{C}_{2}$, then the low voltage battery can be used (in this case $50 \mathrm{~V}$ ) to store energy from the input energy source or from the ac grid. The simulation results are shown in Fig.9. In the example passive components with high values are used to limit current pulsations.

In battery charge mode (Fig. 10, Fig. 11.) the power can be regulated in a wide range. It is possible to store energy from the grid or from the input source or from both of the sources. The voltages of the input source and battery must be selected so that the value calculated (7) is as close as possible to the nominal dc bus voltage.

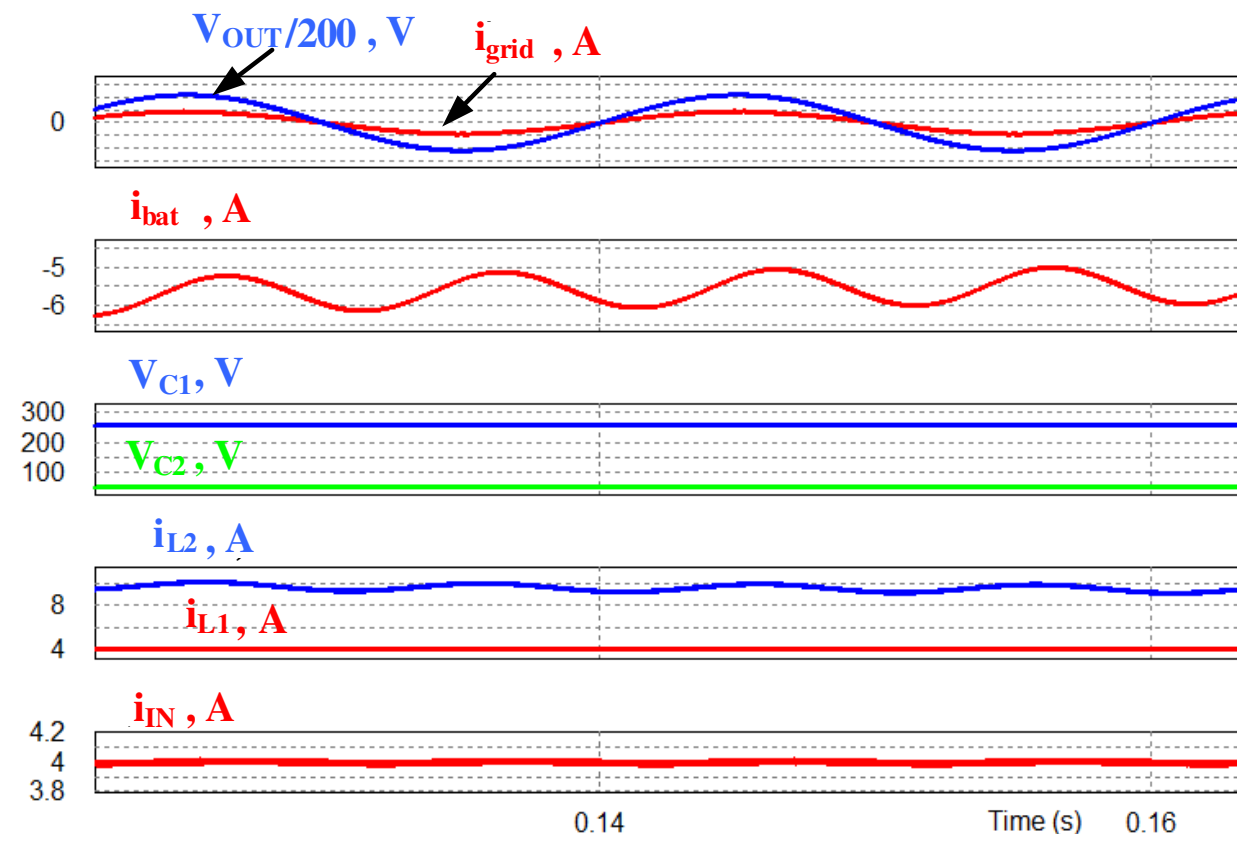

Fig. 10. Waveforms qZSI with battery in parallel to upper capacitor in charge mode

$L_{1}=L_{2}=1400 \mu \mathrm{H}, C_{1}=C_{2}=4000 \mu \mathrm{F}, C_{I N}=1000 \mu \mathrm{F}, V_{I N}=200 \mathrm{~V}, V_{B A T}=50 \mathrm{~V}, R_{B A T}=0.5 \Omega$

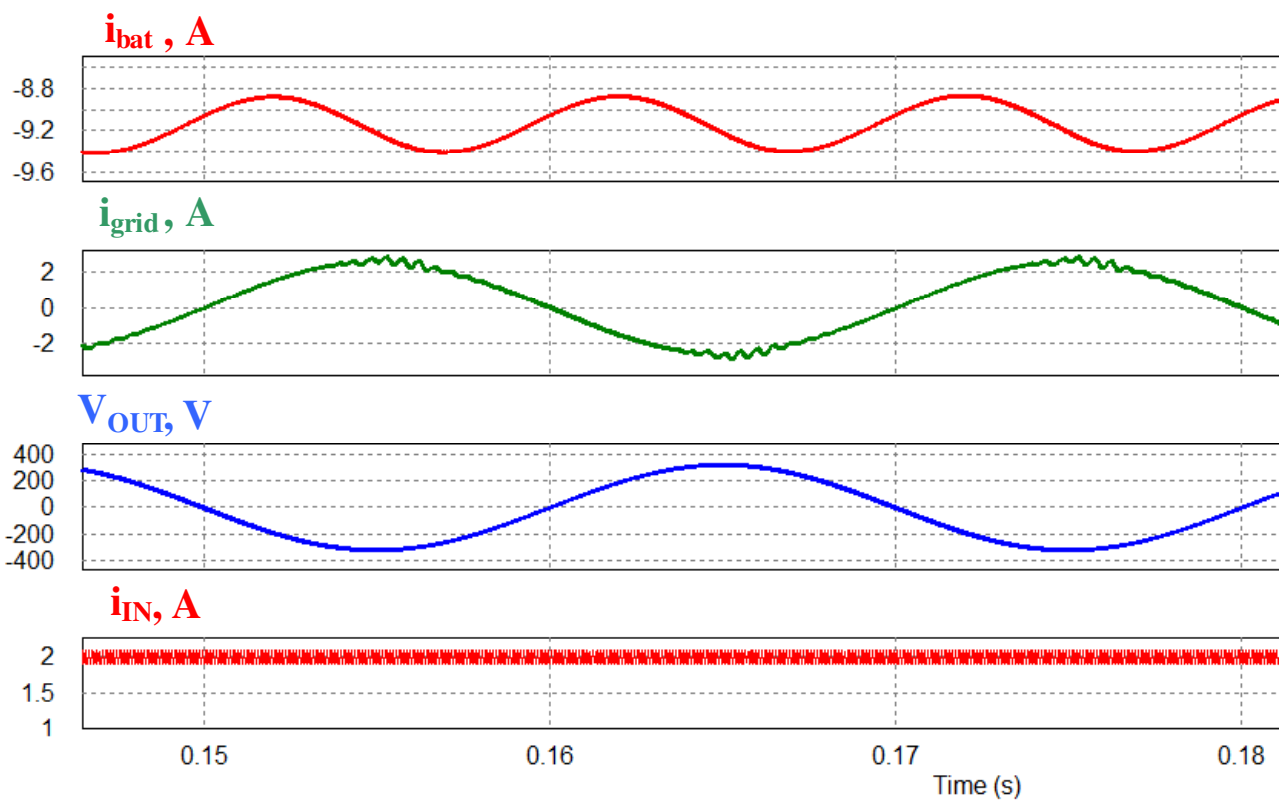

Fig. 11. Waveforms qZSI with battery in parallel to upper capacitor in charge mode from input source and battery, $L_{1}=L_{2}=1400 \mu \mathrm{H}, C_{1}=C_{2}=4000 \mu \mathrm{F}, C_{I N}=1000 \mu \mathrm{F}$,

$$
V_{I N}=200 \mathrm{~V}, V_{B A T}=50 \mathrm{~V}, R_{B A T}=0.5 \Omega
$$




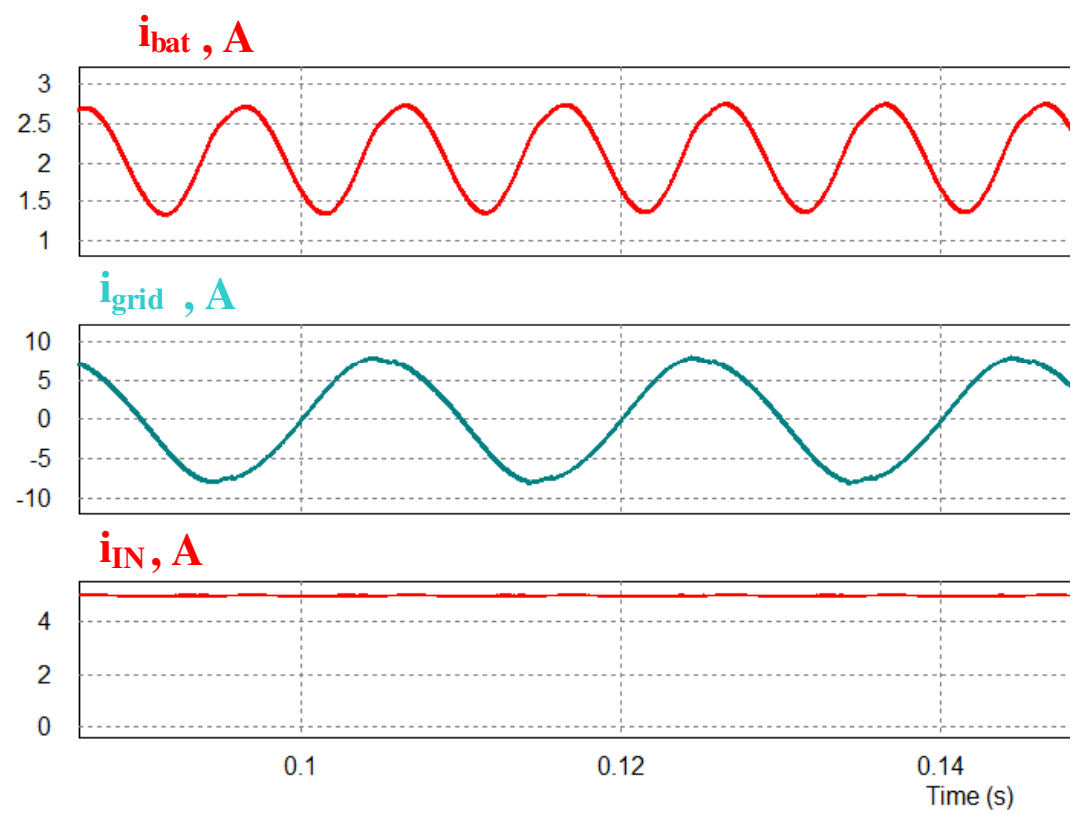

Fig. 12. Waveforms qZSI with battery in parallel to upper capacitor in discharge mode $L_{1}=L_{2}=1400 \mu \mathrm{H}, C_{1}=C_{2}=4000 \mu \mathrm{F}, C_{I N}=1000 \mu \mathrm{F}, V_{I N}=200 \mathrm{~V}, V_{B A T}=100 \mathrm{~V}$

In Fig. 12. the waveform is shown during the discharge mode. This mode is very limited as shown by (10) - (12). In Fig. 12 almost maximum power is shown that can be transferred to the grid by the particular input generation. The change in the battery voltage that imitated operation of the dc-dc converter enabled increase of the discharge power range, but did not solve this limitation fully. As the most important mode for storage that is integrated in the renewable energy source generation system is supply power to the grid or load when the generation is weak, the discharge limitation makes this topology inappropriate for such application. Changing of the input voltage in the simulation model confirms that operation with low input voltage without modification of the schematics is not possible.

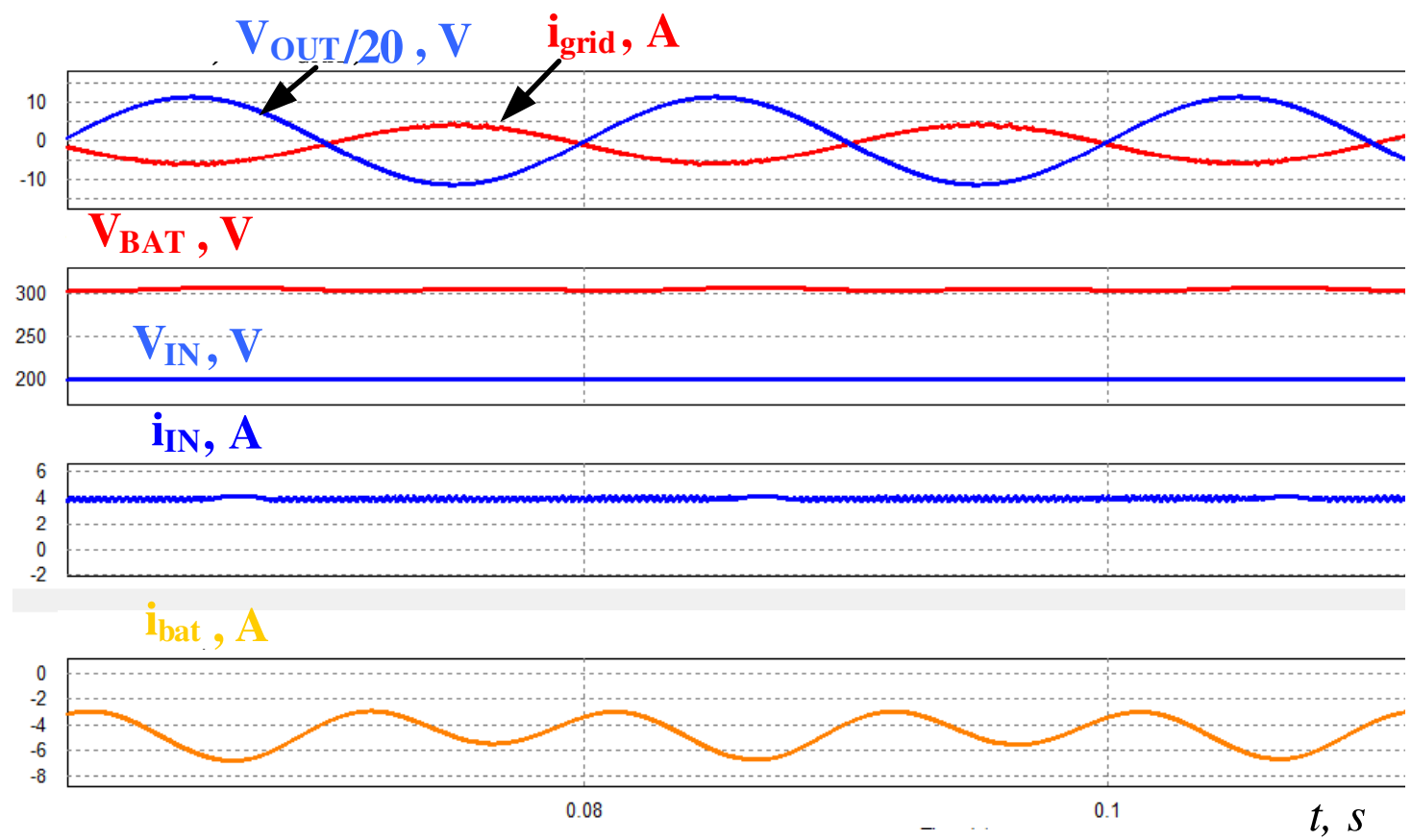

Fig. 13. Waveforms qZSI with battery in parallel to $C_{1}$ during energy storing from grid and input source, $L_{1}=L_{2}=1400 \mu \mathrm{H}, C_{1}=C_{2}=4000 \mu \mathrm{F}, C_{I N}=1000 \mu \mathrm{F}, V_{I N}=200 \mathrm{~V}, R_{B A T}=2 \Omega$,

$$
V_{B A T}=300 \mathrm{~V}
$$


Fig. 13. shows the simulation results in case if the battery is connected in parallel to the lower capacitor $C_{1}$, then the high voltage battery should be used (in this case $300 \mathrm{~V}$ ) to store energy from the input energy source or from the ac grid. The simulation results in battery charge mode are shown in Fig. 13. The power from the battery can be regulated in a wide range in both charge and discharge modes, but the high voltage battery has higher series resistance and also the voltage depends on the state of the charge.

\section{Conclusions}

In the paper analysis of the scientific papers about energy stored qZSI and also theoretical and simulation based analysis of basic relations and control principles are given. In the paper it is shown that energy stored by the quasi $\mathrm{Z}$ source inverter can be realized by using a small number of semiconductor devices and by implementing a relatively simple control algorithm. The design of the phase locked loop and proportional resonant controller is discussed in the paper. The control of input and battery power can be realized by regulating the shoot through duty cycle and modulation index. The control loop can be further improved by introducing the dc bus voltage control loop. One of the problems is $100 \mathrm{~Hz}$ current ripple in the battery or input source current that can be removed by increasing the values of the passive components, but that will decrease the power density of the converter, therefore introduction of an advanced control method or active filter for solving this problem should be investigated. Connecting the battery in parallel to the upper capacitor allows using the low voltage battery, but the discharge mode has power limitations that limit the practical application range of this energy stored qZSI. Connecting the battery in parallel to the lower capacitor has no power limitations, but usage of the high voltage battery is less attractive in many applications.

\section{Acknowledgement}

This research work has been supported by the Latvian Council of Science (Grant 673/2014).

\section{References}

1. Singh B., Singh B. N., Chandra A., Al-Haddad K., Pandey A., Kothari D. P. "A review of singlephase improved power quality AC-DC converters," IEEE Transactions on Industrial Electronics, vol. 50, no. 5, pp. 962-981, Oct. 2003.

2. Kroics K. "Bi-directional two level 6-phase DC-DC converter for energy storage application," in Proceedings of PCIM Europe 2015; International Exhibition and Conference for Power Electronics, Intelligent Motion, Renewable Energy and Energy Management, 2015, pp. 1-8.

3. Kroics K., Zakis J., Sirmelis U. "Multiphase interleaved DC-DC converter with directly and inversely coupled inductors," in 2016 57th International Scientific Conference on Power and Electrical Engineering of Riga Technical University (RTUCON), 2016, pp. 1-6.

4. Zhang N., Sutanto D., Muttaqi K. M. "A review of topologies of three-port DC-DC converters for the integration of renewable energy and energy storage system," Renewable and Sustainable Energy Reviews, vol. 56, pp. 388-401, Apr. 2016.

5. Husev O. et al., "Comparison of Impedance-Source Networks for Two and Multilevel Buck Boost Inverter Applications," IEEE Transactions on Power Electronics, vol. 31, no. 11, pp. 75647579, Nov. 2016.

6. Battiston A., Martin J. P., Miliani E. H., Nahid-Mobarakeh B., Pierfederici S., Meibody-Tabar F. "Comparison Criteria for Electric Traction System Using Z-Source/Quasi Z-Source Inverter and Conventional Architectures," IEEE Journal of Emerging and Selected Topics in Power Electronics, vol. 2, no. 3, pp. 467-476, Sep. 2014.

7. Panfilov D., Husev O., Blaabjerg F., Zakis J., Khandakji K. "Comparison of three-phase threelevel voltage source inverter with intermediate dc-dc boost converter and quasi-Z-source inverter," IET Power Electronics, vol. 9, no. 6, pp. 1238-1248, 2016.

8. Vinnikov D., Chub A., Kosenko R., Zakis J., Liivik L. "Comparison of Performance of PhaseShift and Asymmetrical Pulse Width Modulation Techniques for the Novel Galvanically Isolated Buck-Boost DC-DC Converter for Photovoltaic Applications," IEEE Journal of Emerging and Selected Topics in Power Electronics, vol. PP, no. 99, p. 1, 2016. 
9. Zeng J., Qiao W., Wei C., Qu L. "A soft-switched three-port single-stage inverter for photovoltaic-battery systems," in 2015 IEEE Energy Conversion Congress and Exposition (ECCE), 2015, pp. 4568-4573.

10. Liivik L., Chub A., Vinnikov D., Zakis J. "Experimental study of high step-up quasi-Z-source DC-DC converter with synchronous rectification," in 2015 9th International Conference on Compatibility and Power Electronics (CPE), 2015, pp. 409-414.

11. Khajesalehi J., Hamzeh M., Sheshyekani K., Afjei E. "Modeling and control of quasi Z-source inverters for parallel operation of battery energy storage systems: Application to microgrids," Electric Power Systems Research, vol. 125, pp. 164-173, Aug. 2015.

12. Zakis J., Vinnikov D., Roasto I., Ribickis L. "Quasi-Z-source inverter based bi-directional DC/DC converter: Analysis of experimental results," in 2011 7th International Conference-Workshop Compatibility and Power Electronics (CPE), 2011, pp. 394-399.

13. Liu Y., Ge B., Abu-Rub H., Peng F. Z. "Control System Design of Battery-Assisted Quasi-ZSource Inverter for Grid-Tie Photovoltaic Power Generation," IEEE Transactions on Sustainable Energy, vol. 4, no. 4, pp. 994-1001, Oct. 2013.

14. Ge B. et al., "An Energy-Stored Quasi-Z-Source Inverter for Application to Photovoltaic Power System," IEEE Transactions on Industrial Electronics, vol. 60, no. 10, pp. 4468-4481, Oct. 2013.

15. Anderson J., Peng F. Z. "Four quasi-Z-Source inverters," in 2008 IEEE Power Electronics Specialists Conference, 2008, pp. 2743-2749.

16. Siwakoti Y. P., Peng F. Z., Blaabjerg F., Loh P. C., Town G. E., Yang S. "Impedance-Source Networks for Electric Power Conversion Part II: Review of Control and Modulation Techniques," IEEE Transactions on Power Electronics, vol. 30, no. 4, pp. 1887-1906, Apr. 2015.

17. Roasto I., Vinnikov D., Zakis J., Husev O. "New Shoot-Through Control Methods for qZSIBased DC/DC Converters," IEEE Transactions on Industrial Informatics, vol. 9, no. 2, pp. 640-647, May 2013.

18. Li Y., Anderson J., Peng F. Z., Liu D. "Quasi-Z-Source Inverter for Photovoltaic Power Generation Systems," in Twenty-Fourth Annual IEEE Applied Power Electronics Conference and Exposition, 2009. APEC 2009, 2009, pp. 918-924.

19. Liu Y., Ge B., Abu-Rub H., Peng F. Z. "Control System Design of Battery-Assisted Quasi-ZSource Inverter for Grid-Tie Photovoltaic Power Generation," IEEE Transactions on Sustainable Energy, vol. 4, no. 4, pp. 994-1001, Oct. 2013.

20. Galkin I., Vorobyov M. "Optimizing of sampling in a low-cost single-phase instantaneous ACgrid synchronization unit with discrete calculation of derivative function," in IECON 2015 - 41st Annual Conference of the IEEE Industrial Electronics Society, 2015, pp. 004538-004543.

21. Roasto I., Jalakas T., Husev O. "Modeling of grid-connected quasi-Z-source series resonant topology based microinverter," in 2016 10th International Conference on Compatibility, Power Electronics and Power Engineering (CPE-POWERENG), 2016, pp. 192-195.

22. Kroics K., Zakis J., Suzdalenko A., Gaigals G. "A simplified approach to input voltage balancing for series connected isolated DC-DC converters," in 2016 18th European Conference on Power Electronics and Applications (EPE'16 ECCE Europe), 2016, pp. 1-10.

23. Han Y., Luo M., Zhao X., Guerrero J. M., Xu L. "Comparative Performance Evaluation of Orthogonal-Signal-Generators-Based Single-Phase PLL Algorithms: A Survey," IEEE Transactions on Power Electronics, vol. 31, no. 5, pp. 3932-3944, May 2016.

24. Kuperman A. "Proportional-Resonant Current Controllers Design Based on Desired Transient Performance," IEEE Transactions on Power Electronics, vol. 30, no. 10, pp. 5341-5345, Oct. 2015.

25. Sun D., Ge B., Bi D., Peng F. Z. "Analysis and control of quasi-Z source inverter with battery for grid-connected PV system," International Journal of Electrical Power \& Energy Systems, vol. 46, pp. 234-240, Mar. 2013. 